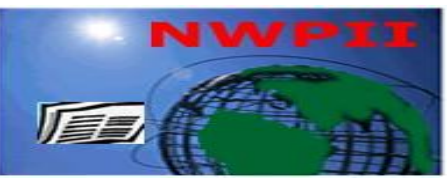

American Journal of Biomedical Sciences

ISSN: 1937-9080

nwpii.com/ajbms

\title{
The Application of Nanotechnology in Medical Sciences: New Horizon of Treatment
}

\author{
Abu Mohammad Azmal Moshed ${ }^{1 *}$, Mohammad Khairul Islam Sarkar ${ }^{2}$, Md. Abdul Khaleque ${ }^{2}$ \\ ${ }^{1}$ Department of Chemistry, Primeasia University, Dhaka-1213, Bangladesh \\ ${ }^{2}$ Department of Environmental Science, Independent University, Bangladesh (IUB) Dhaka-1212, Bangladesh \\ *Corresponding Author \\ Abu Mohammad Azmal Morshed \\ Department of Chemistry \\ Primeasia University \\ Dhaka-1213, Bangladesh \\ Cell: +88-01674643058 \\ Email: azmal.morshed@gmail.com
}

Received: 07 September 2016; | Revised: 27 November 2016; | Accepted: 12 February 2017

\begin{abstract}
Nanotechnology has become enormously promising technology during last few decades and now it is estimated to have a significant effect on medical equipment. The possible effects of novel nanomedical applications on sickness identification, treatment, as well as anticipation are expected to improve healthiness care greatly. In addition, therapeutic selection may gradually be adapted to all patients' profile. Applications of nanomaterials are reported in operation, cancer diagnosis as well as therapy, biodetection of sickness markers, molecular imaging, implant technology, tissue engineering, as well as devices for drug, protein, and gene and radionuclide release. Various medical nanotechnology applications are at a standstill in their immaturity. A larger amount of nanodevices are presently under medical examination as well as several devices are commercially available. In this review work some applications of nanodevices in medical technology are also summarized.
\end{abstract}

Keywords: Nanotechnology, Medical technology, Biosensors, Molecular imaging, Cancer diagnostics etc.

\section{Introduction}

Nanotechnology is an improving technology for the exploitation of individual technological advancements of controlling the structure of materials at a reduced dimensional scale that may approach individual molecules as well as their organized aggregates or supramolecular structures. The application of nanotechnology to medicine can provide several benefits, especially in oncology, and this has resulted in the emergence of a new research field called Nanooncology [1]. Drug-loaded nanoparticles provide a promising solution by selectively targeting tumor cells, thereby preventing damage to healthy cells [2]. Nanoparticles can be engineered to incorporate a wide variety of chemotherapeutic or diagnostic agents, creating 
flexibility in their design that is not possible with other types of drug delivery systems [3]. Information in nanoscience as well as nanotechnology is growing in the whole World, leading to large scientific progresses. In turn, this is expected to lead to elementary changes in the way that equipments, medical devices, as well as systems are understood as well as created. Application in life sciences research, on the whole at the cell level sets the stage for an exciting role of nanotechnology in healthcare [4].

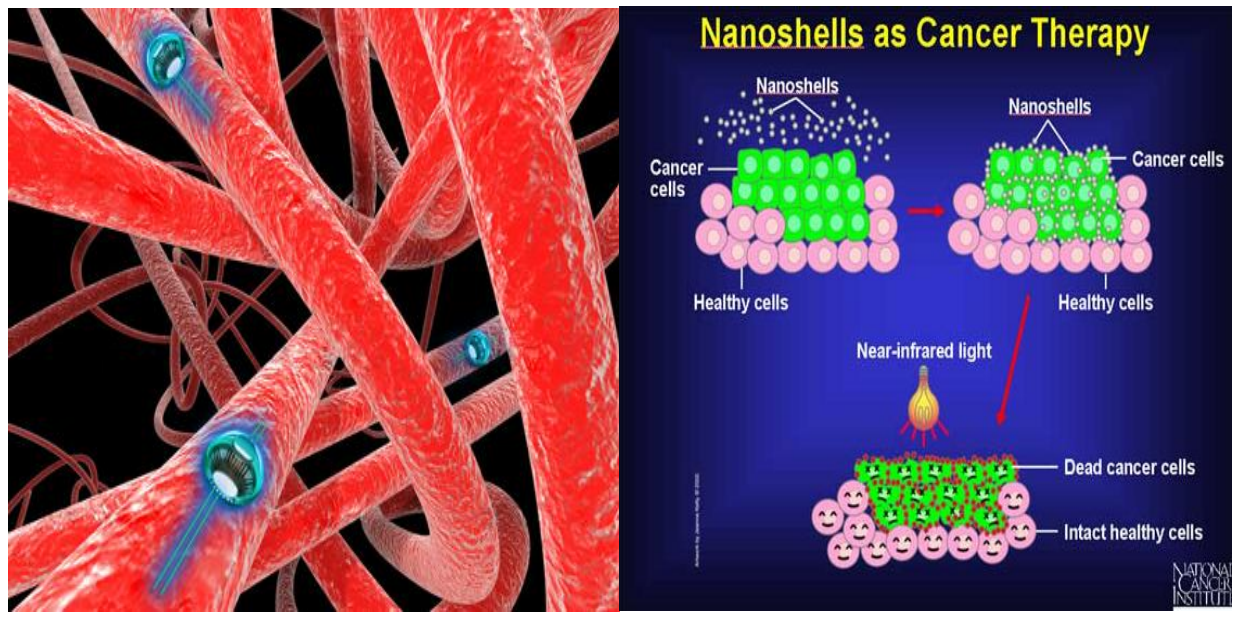

Figure 1. Applications of Nanotechnology in Medical Science. (Diagnosis of medical conditions will be performed using new screening assays enabled by nanotechnology-powered devices that can analyze a patient's physiological sample for dozens of molecular signatures associated with particular medical conditions)

\section{Nanotechnology on Duty in Medical Applications}

\section{Biosensors}

Biosensors are chemical sensors in which identification processes depend on biochemical mechanisms operation. They made up of a biological factor responsible for sampling, as well as a physical element (often called transducer) transmitting sampling outcome for moreover processing [5-8]. The biological element of a biosensor contains a biosensitive layer, which can either contain bioreceptors or be made of bioreceptors covalently attached to the transducer.Concerning the biological specificity conferring mechanism used one can distinguish 5 major categories of biosensors

1) Antibody/antigen based,

2) Enzymes based (mono- or multi enzyme systems) [9],

3) Nucleic acids based (DNA, cDNA, RNA) [10]

4) Based on cellular interactions (cellular structures/cells),utilisating the whole cells (microorganisms, such asbacteria, fungi, eukaryotic cells or yeast) or cell organellesor particles (mitochondria, cell walls, tissue slices) [11-16]

5) Employing biomimetic materials (e.g., synthetic bioreceptors).

Biosensors based on nucleic acid interactions of biological element are called DNA biosensors, or genosensors, or biodetectors. They are used to identify small concentrations of DNA (microorganism like virus or bacteria) in a large sample. This relies on comparing sample DNA with DNA of known organism (DNA probe).

There are different types of nanoparticles that can be utilized as biosensors components. Most of them work as probes identifying as well as differentiating an analytic of interest for diagnostic as well as screening purposes. In such applications biological molecular species are attached to the nanoparticles through a proprietary modification procedure. The probes are utilized then to bind as well as signal the presence of a target in a sample by their color, mass, or other physical properties. The molecular binding is a subject of the biological surface 
science [17], which is strongly related to the research on modification of nanostructures properties by controlling their structure and surface at a nanoscale level [18,19]. Both fields cover broad area in which one can locate the use of nanostructured platinum-lipid biolayer composite as biosensor [20] or research on endothelisation as well as adherence of the cells to nanostructure surfaces [21]. Biosensors based on quantum dots, nanobarcodes, metallic nanobeads, silica nanoparticles, magnetic beads, as well as carbon nanotubes can be skilled to the group of nanoprobes. The other biosensors employ nanoparticles in a dissimilar way.

It can also be regarded as one more implementation of nanotechnology in the field of medical science and diagnostics. One of the main important issues is the proper circulation of drugs as well as other therapeutic agents within the patient's body [22].

\section{Drug delivery}

Targeting the delivery of drugs to diseased lesions is one of the significant aspects of the drug delivery systems. To convey a enough dose of drug to the lesion, appropriate carriers of drugs are wanted. Nano- as well as micro-particle carriers have significant potential applications for the administration of therapeutic molecules. Liposomes have been utilized as potential drug carriers instead of conventional dosage forms for the reason that of their unique advantages, which include the capability to protect drugs from degradation, target the drug to the site of achievement, as well as decrease the toxicity of side effects [23]. However, developmental work on liposomes has been limited due to inherent problems such as low encapsulation efficiency, rapid leakage of water-soluble drugs in the presence of blood components, as well as poor storage stability. Thus most of the early clinical studies with liposomes met with failure because the injected vesicles were rapidly removed by phagocytic cells of the immune system. This obstacle has now been overcome with the development of so called 'stealth liposomes' that contain an outer coating of a synthetic polymer that protects the liposomes from immune destruction [24]. In some cases, nanoparticles are more efficient drug carriers than liposomes due to their better stability [25] as well as possess more functional control release properties. These are the reasons why a lot of drugs have been associated with nanoparticles (e.g., antibiotics, antiviral as well as antiparasitic drugs, cytostatics, vitamins, protein as well as peptides, including enzymes as well as hormones). Drug delivery systems can be classified according to (1) their physical form or (2) their functional properties. In the latter case three groups have been proposed, called first-, second- and third generation systems. [26].
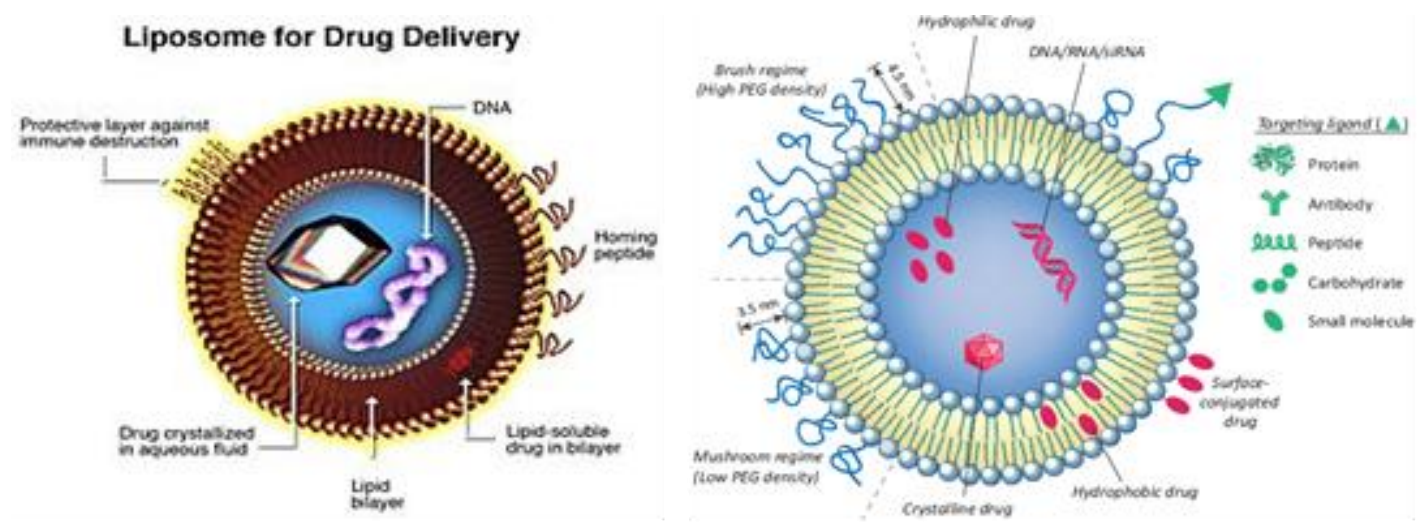

Figure 2. Liposome for Drug Delivery System.

First generation systems. This group includes microcapsules and microspheres for control chemoemobilisation and control release of proteins and peptides or for drug delivery within the brain. Although they are capable of delivering the active substances specifically to the intended 
target, they have to be implanted as closely as possible to the site of action, and therefore they cannot be considered as 'carriers'.

Second generation systems. To this group belong so called true carriers: liposomes, nanocapsules, and nanospheres (called passive colloidal carriers), and certain active carriers which release their contents after a specific signal, such as temperature-sensitive liposomes and magnetic nanospheres. They are less than 1 $\mathrm{mm}$ in diameter and are capable of releasing an active product at the intended target carrying it there after administration by a general route. Their usage is limited as they are rapidly removed from the circulation by phagocytic cells and cannot cross normal capillary endotherium.

Third generation systems. The third generation systems are also true carriers based on monoclonal antibodies, which are characterized by capability of specific recognition. To this group belong monoclonal antibodies per se and liposomes, nanoparticles (nanocapsules and nanospheres) piloted by monoclonal antibodies or their ligands.

In current years, biodegradable polymeric nanoparticles have attracted considerable attention as potential drug delivery devices with the prospects of their applications in controlling drug release, their capability to target particular organs/tissue, as carriers of oligonucleotides in antisense therapy, DNA in gene therapy, as well as in their capability to distribute proteins, peptides as well as genes through oral administration [27]. The use of colloidal particulate carrier systems $(25 \mathrm{~nm}$ to $1 \mathrm{~mm}$ in diameter) for drug delivery is discussed by Barratt in his review [28].

\section{Encapsulation of drugs with nanomaterials}

Encapsulation is an attractive delivery option for a variety of drugs [29]. The use of nanocapsules as drug carriers is associated with a number of advantages. For example, poly(alkylcyanocrystalate) nanocapsules were shown to protect insulin from degradation by digestive enzymes in vitro and to pass across the interstinal mucosa[30]. It was also reported that (in rat) encapsulation of somatostatin analogue within nanocapsules given by oral route improved and prolonged its therapeutic effect [31] while encapsulation in chitosan nanoparticles improved a nasal absorption of insulin [32]. Moreover, encapsulation provides effective protection of the gastrointestinal mucosa, which was shown e.g., by reducing the sideeffects of diclofenac [33] encapsulated in poly (lactic acid) nanocapsules and also by reducing drug-related irradiation, e.g., after administration in the intramuscular route [34]. To make drug carriers 'invisible' to macrophages and thus to reduce their uptake by phagocytic cells, a special strategy has been applied for preparation of matrix-structured nanospheres. Neutral and cationic lipids form a bilayer liposome with hydrophobic (inside the spherical structure) and hydrophilic (outside) parts. Negatively charged plasmid DNA molecules carrying therapeutic DNA fragments are not able to enter the cells due to the electrostatic interaction with the cell membrane (Figure-2). DNA assembly within the central cavity of cationic liposomes results in lipoplex generation. In this form, the plasmid (as a part of a lipoplex) can enter the cells via endocytosis, DNA molecules are released; they enter the cell nucleus, where transcription and translation of a 'corrected' gene take place. The technique is based on the nanoparticle Surface modification, e.g., with poly (ethylene glycol) (PEG) [35, 36] that provides a 'cloud' of hydrophilic chains at the nanoparticle surface repelling plasma proteins. For example, this kind of particle has been loaded with tamoxifen for antiestrogen therapy in the treatment of hormonedependent tumours[37]. Nanoparticles prepared from PLGA- PEG co-polymers have been shown to increase the circulating half-life of cisplatine[38]. Similar approaches have been applied to the reservoir-type polymer based drug carrier nanocapsules with the aim of creating long-circulating systems with a high loading capacity of lipophilic drugs [39],e.g., in solid tumours treatment nanocapsules made of PLAPEG loaded with tetra (hydroxyphenyl) chlorin were used [40]. Another strategy for preparing long-circulating colloidal systems can be considered as biomimetic in that it seeks to imitate cells or pathogens, which avoid phagocytosis by reducing or inhibiting 
complement activation. e.g., heparin, the anionic polysaccharide anticoagulant, enabled to inhibit several steps of the complement cascades, can be used to modify the surface of nanoparticles and provide a biomimetic effect [41]. Metal nanoshells are concentric sphere nanoparticles consisting of a dielectric (typically gold sulphide or silica) core and a metal (gold) shell. By varying the relative thickness of the core as well as shell layers, the Plasmon-derived optical resonance of gold can be shifted in wavelength.
By varying the complete dimension of the gold nanoshell, it can be made to either selectively absorb (for particles diameters $<75 \mathrm{~nm}$ ) or scatter occasion light. When optically interesting gold nanoshells are embedded in a matrix, illuminating them at their resonance wavelength causes the nanoshells to move heat to their local environment. This photo thermal outcome can be utilized to optically remote control drug release in a nanoshell-polymer composite drug material. [42].
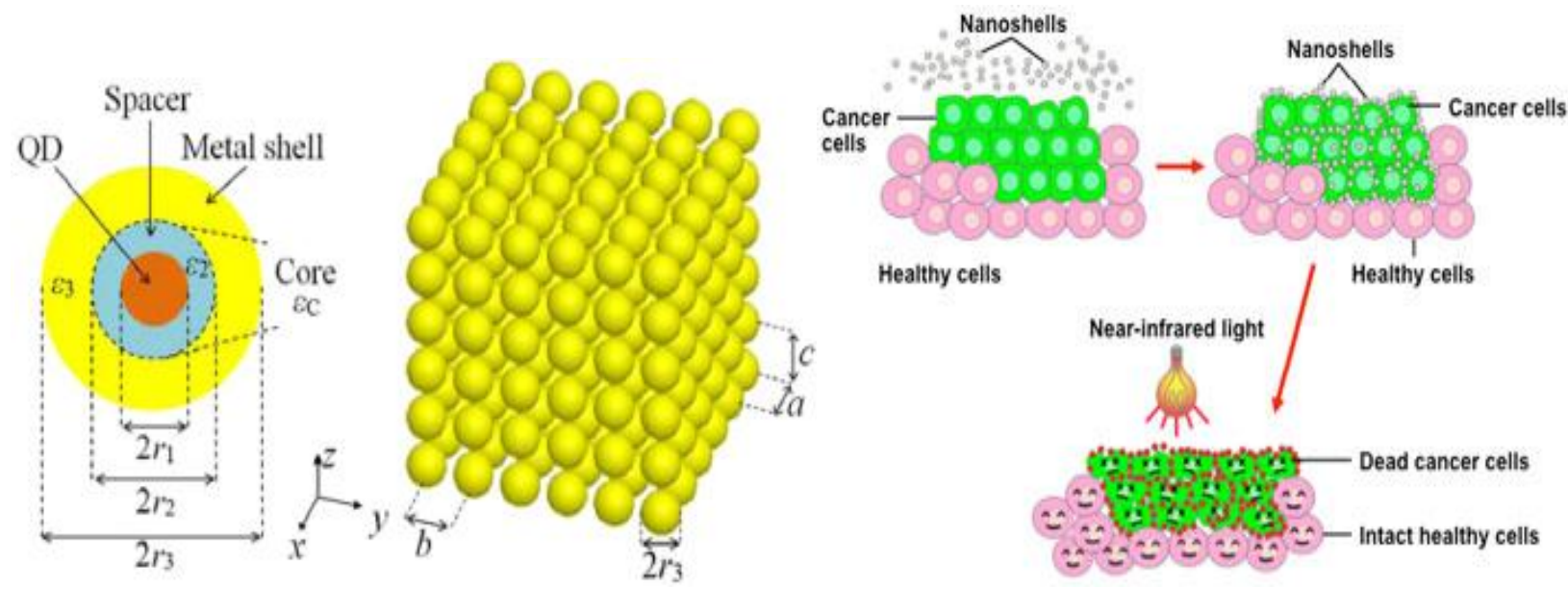

Figure 3. (a) Metal nanoshell and (b) Nanoshells kill tumor cells selectively.

Antisense therapy. Nucleic acids can be utilized not just to diagnose as well as monitor but also to prevent as well as cure diseases as they constitute the bases of antisense as well as gene therapies. Application of an antisense strategy to regulate the transcription of disease-related genes in vivo has an important therapeutic potential to treat or cure a variety of diseases and abnormal physiological conditions. In theory, an antisense oligonucleotide is a little portion (15-20 bp) of deoxynucleotides characterized by a sequence balancing to a part of the targeted mRNA. The target of the antisense strategy is to interface with gene expression by preventing the change of proteins from mRNA. There are the minority mechanisms of mRNA inactivation [43], including (i) sterical blocking of mRNA by antisense binding as well as destruction antisense-mRNA hybrids by Rnase H-enzyme, (ii) formation of triple helix between genomic double-stranded DNA as well as oligonucleotides, or (iii) the cleavage of target RNA by ribozymes. Antisense oligonucleotides have emerged as potential gene-specific therapeutic agents as well as are presently undergoing evaluation in clinical trials for a variety of diseases. These include advanced carcinoma [44-47], non-Hodgkin's lymphoma [48,49], acute myeloid or lymphoblastic leukemia [50] as well as chronic myelogenous leukemia (CML) [51]. Antisense oligonucleotides are molecules that are capable to inhibit gene expression, being therefore potentially dynamic for the treatment of viral infections or cancer disease. However, the difficulties such as the poor strength of antisense oligonucleotides versus nuclease activity in vitro as well as in vivo, as well as their low intracellular penetration have restricted their use in therapeutics [52, 53]. In order to rise their straightly, recover cell penetration as well as also avoid non-specific aptameric property (leading to non-specific binding of antisense 
oligonucleotides), the utilize of liposomes or nanoparticles such as liposomes or nanoparticles, has been considered [22]. Very in recent times, it was reported that antisense oligonucleotides could be encapsulated in nanocapsules with a size of $350-100 \mathrm{~nm}$. A formulation of these capsules might have special importance for oligonucleotide delivery. The first researches on the treatment of RAS cells expressing the pointmutated Ha-ras gene were promising [54]. In a different approach, nanocapsules loaded with an aqueous core have been improved for the encapsulation of antisense oligonucleotides. They were illustrated to successfully look after oligonucleotides from degradation in biological fluids, e.g., in an experimental model of Ewing sarcoma for phosphotrioateantisense oligonucleotides directed against EWS Fli-1 chimeric RNA [55]. It is also worthy to mention recently described nucleic acid molecules that can find practical applications in antisense therapy, named small interfering RNA, or siRNA. siRNA [56, 57]. siRNA is a short RNA duplex between 15 to 21 nucleotides in length. These duplexes have two-nucleotide overhangs on their 3-prime ends as well as are phosphorylated on their 5-prime ends. They can be utilized for, so-called, gene silencing. Once transfected into cells, siRNA in conjunction with cellular machinery, targets messenger RNA molecules containing an identical sequence for degradation in a catalytic manner. The degraded message is no longer functional in translation (the biosynthesis of protein) as well as thus in the expression of the corresponding gene. Designers RNA molecules targeting a gene of significance can be transfected into cells to suppress the expression of that gene. Moreover, the effects of the suppression can then be assayed by a number of different biochemical, molecular and cellular biology methods to understand the role of the gene in biological model system under study. On the other hand, also very recently, a successful ODN based approach termed decoy ODN has used synthetic ODN containing an enhancer element that can penetrate cells, to bind to sequence-specific DNA-binding proteins and interfere with transcription in vitro and in vivo.

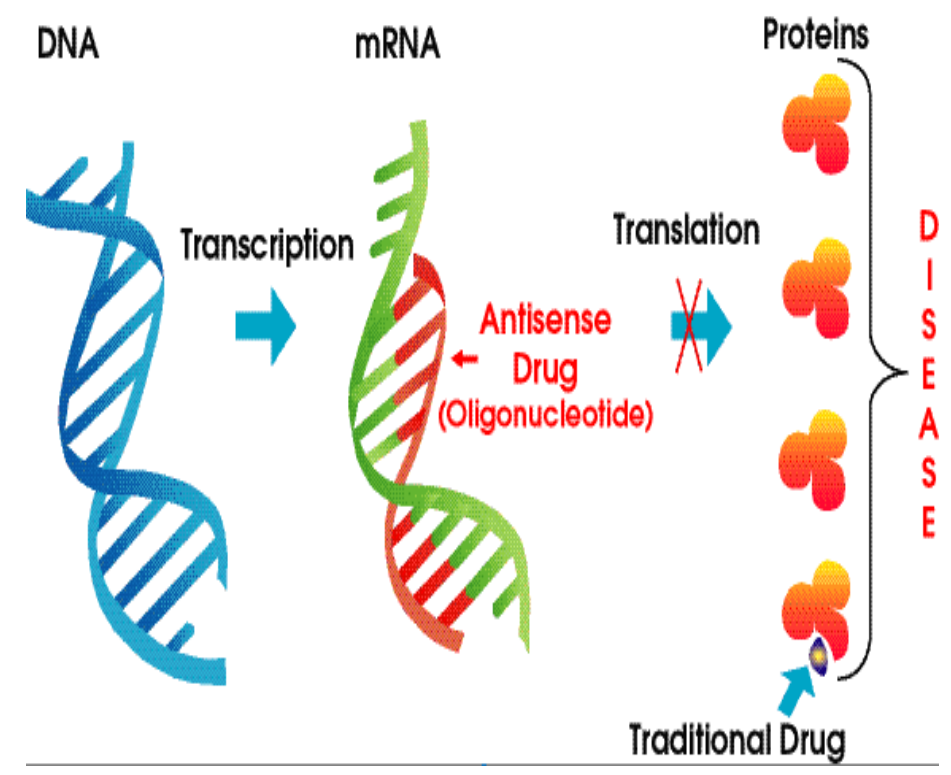

Figure 4. Antisense Technology. 


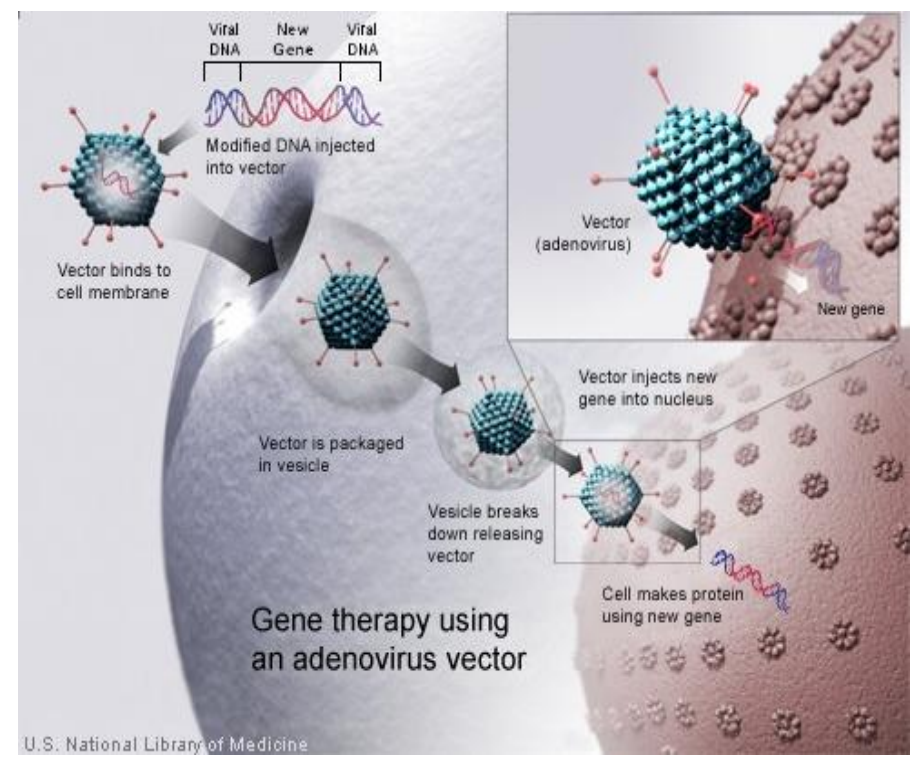

Figure 5. Gene therapy.

Transfection of cis-element double-stranded ODN (decoy ODN) results in attenuation of the authentic cis-trans interaction, leading to removal of trans-factors from the endogenous cis-elements with subsequent modulation of gene expression [58]. The principles of the decoy strategy and how to design decoy ODN can be found in Tomita et al. report [59]. This approach provides a new powerful tool in a new class of anti-gene strategies to treat various diseases or as a research tool to examine the molecular mechanisms of expression of a specific gene.

\section{Gene Therapy as well as Administration of DNA Vaccines:}

Gene therapy is a currently introduced technique for the treatment or prevention of genetic disorders by correcting defective genes responsible for disease improvement based on delivery of repaired, or the replacement of incorrect genes. The most common approach for correcting faulty genes is insertion of a normal gene into a nonspecific location within the genome to replace a nonfunctional gene. An abnormal gene could be also swapped for a normal gene through homologous recombination or repaired through selective reverse mutation, which returns the gene to its normal function. There is the wide range of target cells as well as diseases, like cancer, infectious, cardiovascular, monogenic (e.g., hemophilias) diseases, as well as rheumatoid arthritis for which clinical or medical studies are ongoing [60, 61]. In fact, the first time disease approved for gene therapy treatment was adenosine deaminase (ADA) deficiency, and the first two patients were treated with intramuscular injections of pegylated bovine ADA (PEG-ADA) in September 1990. Now a day, over 13 years later, [62]. Reported the results of long-term follow-up and data collected from these original patients, which provided novel information about the longevity of $\mathrm{T}$ lymphocytes in humans and persistence of gene expression in vivo from vectors. In another more, one of the most recent information on gene therapy demonstrates the successful treatment of patients with haemophilia- $B$, with a defect in a gene encoding blood coagulation factor IX[63. 64] as well as patients with haemophilia-A having a defect in a gene that encodes factor VIII [65]. In these cases, patients' fibroblasts transfected with a plasmid containing sequences of the factor VIII gene (haemophilia-A treatment) as well as adenoassociated viral vectors expressing human factor IX (haemophilia-B) were utilized for gene transfer. Application of nanotechnological tools in human gene therapy has been reviewed widely by Davis [66]. He described non-viral vectors based on nanoparticles (usually 50-500 $\mathrm{nm}$ in size) that were already tested to transport plasmid DNA. He emphasized that nanotechnology in gene therapy would be applied to replace the 
currently utilized viral vectors by potentially less immunogenic nanosize genecarriers. So deliveries of repaired genes, or the replacement of incorrect genes, are fields where nanoscaled objects could be introduced successfully. On the other hand, genetic immunization with DNA vaccines has emerged as one of the most promising applications of non-viral gene therapy $[67,68]$, having an amount of the potential advantages over conventional vaccines. These are included: (i) the high stability of plasmid DNA, (ii) low manufacturing costs, (iii) lack of infection risk associated attenuated viral vaccines, (iv) the capacity of target multiple antigens to one plasmid, as well as (v) the ability to elicit both humoral as well as cellular immune responses. Until recently, intramuscular injection was the primary route of administration of DNA vaccines. As an another to intramuscular administration of plasmid DNA, researchers have been investigating targeting plasmid DNA to the skin utilizing intradermal needle injection, needle-free jet injection devices, the gene gun, or currently topical supply [69] of formulated plasmid in the form of a patch, cream, or gel .The latter method may provide many advantages in terms of price as well as patient compliance [70]. Among other nanoparticles, chitosan, a biodegradable polysaccharide comprise of primarily Dglucosamine repeating components, has been suggested by different groups as an alternative non-viral delivery system for plasmid DNA. Selective chitosan polymers as well as chitosan oligomers have been found to efficiently condense plasmid DNA as well as to transfect several different cell kinds in vitro as well as in the intestines, colon, nose, as well as lung [69, 71]. Chitosan nanoparticles were also applied for DNA vaccination by the oral route. [72].

Also Saxl [73, 74] in her reports discussed the development of alternative vectors based on synthetic, nonviral systems. She proposed the use of the following nanovectors for gene therapy and DNA vaccines: 1) polymer-DNA complex vectors, in which polymer wrap around the DNA forming particles that range $25-300 \mathrm{~nm}$ in diameter. Practical advantages of such complexes are that the polymer protects the DNA and may also improve the cell transfection efficiency. 2)
liposome-DNA complex vectors, which characterize with DNA condensation within a lipid bilayer (liposome). 3) polymeroligonucleotide complexes. In these complexes peptide nucleic acid (PNA) is delivered to the cell nucleus and the faulty gene is reprogrammed. Their usage may be more beneficial than gene therapy. She also highlights the possible implementation of nanobiomimetics for DNA vectors, including the development of nanoengineered polymeric materials that are bioinspired by viral/toxin strategies.

\section{Nanotechnology to produce artificial cell:}

Another field where the achievements of nanotechnology can be practically utilized is creation of artificial cells, tissues as well as organs. Artificial cells are being actively investigated for utilized in the replacement of defective or wrongly functioning cells and organs, especially related to metabolic functions. The earliest routine clinical use of artificial cells is in the form of coated activated charcoal for hem perfusion. The implantation of encapsulated cells is being studied for the treatment of diabetes, liver failure, kidney failure and the use of encapsulated genetically engineered cells for gene therapy. Artificial cells are also considered for drug delivery and for other uses in biotechnology, chemical engineering and medicine $[75,76]$. The problems in creating the biological systems (artificial cells) are described by Pohorille and Deamer [77].These authors also discussed the potential applications of artificial cell-like structures in pharmacology and medical diagnostics pointing out the properties of an ideal minimal cell. Chang and co-workers presented the future prospects for artificial blood, especially of the artificial red blood cells (RBC) [78, 79, and 80]. Very recently, they have reported the development of new artificial red blood cells that are more like natural RBC. Their novel nanodimension red blood cell substitute is based on ultrathin polyethylene glycolpolylactic acid (PEG-PLA) membrane nanocapsules (80-150 nm diameter) containing hemoglobin $(\mathrm{Hb})$ and enzymes [79]. It is worthy to note that blood substitutes based on modified hemoglobin, polyhaemoglobins (Poly-Hb) and 
perfluorochemicals are already in advanced phase III clinical trials while conjugated haemoglobins are in phase II clinical trial. And the circulation time of the novel artificial RBC studied (containing haemoglobin and RBC enzymes with membrane formed from composite copolymer of PEG-PLA) is double compared to that of Poly- $\mathrm{Hb}$ [80]. More theoretical proposal of an artificial red blood cell is the mechanical red blood cell called respirocyte designed by Freitas [81, 82]. It was the first time detailed design study of a particular medical or clinical nanodevice (of the type proposed by Dexler in "Nanosystems"). The proposed respirocyte is about 1 micron in diameter as well as just flows along the bloodstream. It is a spherical nanorobot creates of 18 billion atoms.

The respirocyte is equipped with a different of chemical, thermal, pressure sensors as well as an onboard nanocomputer. Which device is intended to function as an artificial erythrocyte, duplicating the oxygen $\left(\mathrm{O}_{2}\right)$ as well as carbon dioxide $\left(\mathrm{CO}_{2}\right)$ transport functions of red blood cells, mimicking the function of natural hemoglobin-filled red blood cells? This is expected to be capable of delivering 236 times.

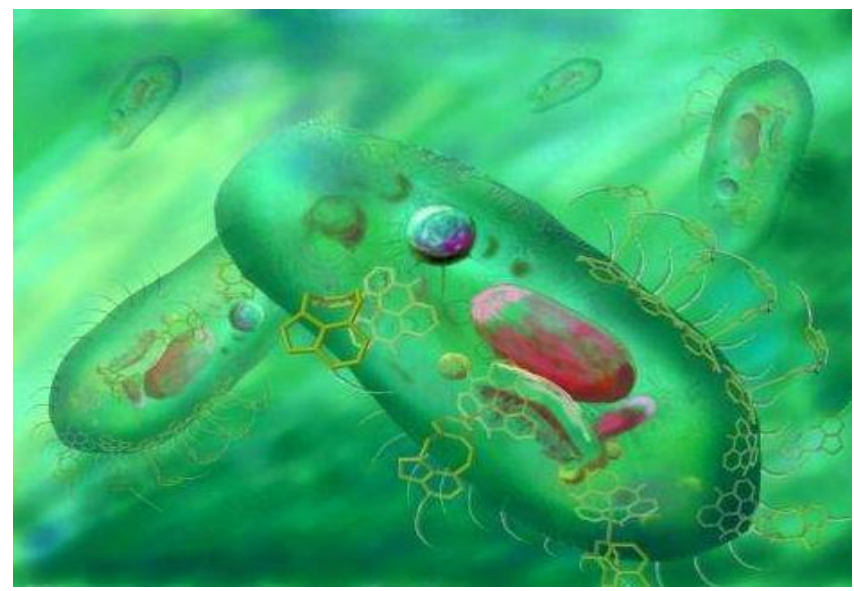

Figure 6. Nano-method transportation by the artificial Cilia nanomaterial cell.

More oxygen $\left(\mathrm{O}_{2}\right)$ per unit volume than a natural red blood cell. Specially installed apparatus enables this device to display a lot of complex responses as well as behaviors. Furthermore, it has been designed to draw power from abundant natural serum glucose supplies as well as thus is capable of operating intelligently as well as virtually indefinitely, whilst red blood cells have a natural lifespan of 4 months. Thus these artificial red blood cells are theoretically capable to supply oxygen $\left(\mathrm{O}_{2}\right)$ as well as can do it even more effectively than an erythrocyte. It could replace defective natural red blood cells in blood circulation. An onboard nanocomputer as well as numerous chemical as well as pressure sensors enables complex device behaviors that are remotely reprogrammable by the physician via externally applied acoustic signals. So far several other nanoscale devices have been described in the literature. Respirocyte is one of the proposals derived from the field of molecular nanotechnology and nanorobot construction with intended practical implementation in medicine $[83,84,85,86]$. It is also expected that the new techniques will allow tissues and organs to be grown artificially on nanopatterned scaffolds to obtain internal tissues implants. In parallel external tissue products are under the development for artificial skin, tissue reconstitution and enhanced wound treatment. Moreover, through biomimickry or minerals laid down as shells and exoskeletons, new bone will be encouraged to grow to heal broken bones and teeth, which could find the practical applications for dental and bone marrow replacement [73, 74]. One of the artificial nanostructures that can interact with as well as replace natural biological materials has been offered by Taton as well as co- 
workers. In the information from one of the meetings of American scientists (American Chemical Society Prospective, Berkeley, California, USA, 2001) Taton [ 87] presented a very intriguing proposal of an artificial bone relying on designing the synthetic substitutes of collagen. Researches on designing selfassembling, synthetic substitutes for collagen have been conducted by a group of Stupp at Northwestern University, Evanston, Illinois. They proposed an artificial material, composed of amphiphilic molecules bearing a long hydrophobic alkyl group on one end as well as ahydrophilic peptide on the other; it was capable to spontaneously assemble into cylindrical structures that resemble collagen fibrils. Moreover, these cylinders guided the formation of hydroxyapatite crystallites. What is even more important, they formed crystallites characterized with orientations as well as shapes similar to those in natural bone. Taton emphasized that these observations lead to a general question: would synthesized nanomaterials be capable not only to replicate the properties of their natural apparatus (cell membranes, tissues as well as bone marrow), but also prompt biological systems to build up on these materials, as well as to produce self-assembling structures? Studies on such nanostructures lead to promising materials with potential utilizes as implants and therapies [22]. Moreover, they may someday show how the cells interact with nanometer-shaped objects in their own world. In future the medical diagnosis, proper as well as efficient deliveries of pharmaceuticals as well as development of artificial cells are the medical or clinical fields where nanosize materials have found practical implementations. As suggested by Freitas, the application of nanotechnology to medicine, nanomedicine, subsumes three mutually overlapping as well as progressively more powerful molecular technologies [88]. First, nanoscale-structured materials as well as devices that can be fabricated today hold great promise for advanced diagnostics as well as biosensors, targeted drug delivery, smart drugs as well as immunoisolation therapies. Second, biotechnology proposes the benefits of molecular medicine via genomics, proteomics as well as artificial engineered microbes. Third, in the longer term, molecular machine systems as well as medical or clinical nanorobots will allow instant pathogen diagnosis as well as extermination, chromosome replacement as well as individual cell surgery in vivo, as well as the efficient augmentation as well as improvement of natural physiological action. There are several other intriguing, still theoretical, proposals for practical functions of nanomechanical tools into the fields of medical or clinical research as well as clinical practice. One action of nanodevices in medical or clinical sciences could be the replacement of defective or incorrectly auctioning cells, such as the respirocyte offered by Freitas [89, 90]. It has also been postulated that nanomachines could distribute drugs within the patient's body. Such nanoconstructions could supply medicines to particular sites making more adequate as well as precise treatment possible [91, 92, and 93]. Such devices would have a small computer, particular binding sites to determine the concentration of specific molecules, as well as a delivery of some 'poison' that could be released selectively. Similar machines equipped with specific 'weapons' could be utilized to remove obstructions in the circulatory system or identify as well as kill cancer cells. It has been also proposed that nanorobots may be modified bacteria and viruses that already have most of the motorisation and target delivery of genetic information [73, 74].Moreover, nanorobots operating in the human body, could monitor levels of individual compounds as well as store that information in internal memory. They could be utilized to rapidly examine a given tissue location, surveying its biochemistry, biomechanics, as well as histometric characteristics in greater detail. This would help in better disease diagnosing [94, 95]. The utilized of nanodevices would give the additional benefits of reduced intrusiveness, improved patient comfort as well as greater fidelity of results, since the target tissue can be examined in its active state in the actual host environment. It is widely anticipated that nanotechnology will continue to evolve and expand in many areas of life and science, and the achievements of nanotechnology will be applied in medical sciences, including 
diagnostics, drug delivery systems and patient treatment over the next couple of years. According to Dr. Brazil from the Royal Society of Medicine (July 2003) opinion: "Nanotechnology provides the potential for significant advances over the next 50 years" with potential applications of: 1) biological nanosensors for diagnostics in the next 1-5 years, 2) generation of artificial muscles, development lab-on-a chip technology for more efficient drug discovery and targeted drug and gene delivery within the next 6-10 year, and 3) later on (after 10-50 years) introduction of nanomachines for in vivo treatment and nanopumps vales for tissue engineering and generation of artificial organs, in health care and medicine. It recommends that more research should concentrate on the complete life cycle of a given nanomaterial in order to identify all exposure situations as well as the workplaces concerned. In parallel, more and more research should beundertaken to guarantee the improvement of "responsible" nanotechnology that integrates health as well as safety considerations [96].

\section{Conclusion}

Finally it could be concluded, although the expectations from nanotechnology in medicine are high and the potential benefits are endlessly enlisted, the safety of nanomedicine is not yet completely defined. Utilize of nanotechnology in medical or clinical therapeutics requires adequate evaluation of its risk as well as safety factors. However, it is probable that nanomedicine in more would play a crucial role in treatment of human diseases as well as also in enhancement of normal human physiology. With concurrent application of nanotechnology in other fields, its utility is likely to extend further into diagnostics, molecular research techniques and tools.

\section{References}

1. Jain KK. Advances in the field of nanooncology. BMC Med 2010; 8: 83. DOI: $10.1186 / 1741-7015-8-83$
2. Misra R, Acharya S, Sahoo SK. Cancer nanotechnology: application of nanotechnology in cancer therapy. Drug Discov Today 2010; 15: 842-850 DOI: 10.1016/j.drudis.2010.08.006

3. Bharali DJ, Mousa SA. Emerging nanomedicines for early cancer detection and improved treatment: current perspective and future promise. Pharmacol Ther 2010; 128: 324-335, DOI: 10.1016/j.pharmthera.2010.07.007

4. Lee PY, Wong KK. Nanomedicine: a new frontier in cancer therapeutics. Curr Drug Deliv 2011; 8: 245-253, DOI: $10.2174 / 156720111795256110$

5. Vo-Dinh, T. and Cullum, B. (2000) Fresenius' Journal ofAnalytical Chemistry 366(6-7), pp.0540-0551.

6. Vo-Dinh, T.; Cullum, B. M. and Stokes, D. L. (2001) Sens.Actuators, B, 74(1-3), pp.2-11. DOI: $10.1016 / \mathrm{S} 0925-4005(00) 00705-\mathrm{X}$

7. Thévenot, D. R.; Toth, K.; Durst, R. A. and Wilson, G. S. (2001) Biosens. Bioelectron., 16(1-2), pp.121 - 131. DOI: $10.1016 / \mathrm{S} 0956-5663(01) 00115-4$

8. Mohanty, S. P. (2001) Biosensors : A Survey Report,

9. Alcala, P.; Ferrer-Miralles, N.; Feliu, J. X. and Villaverde, A.(2002) Biotechnol. Lett., 24(19), DOI: 10.1023/A:1020371220100

10. Kwakye, S. and Baeumner, A. (2003) Anal. Bioanal. Chem., 376, pp.1062-1068. DOI: $10.1007 / \mathrm{s} 00216-003-2063-2$

11. Kitova, A. E.; Kuvichkina, T. N.; Il'yasov, P. V.; Arinbasarova, A.Y., et al. (2002) Appl. Biochem. Microbiol., 38, pp.500-505. DOI: 10.1023/A:1019989023130

12. Köhler, S.; Belkin, S. and Schmid, R. D. (2000) Anal. Bioanal.Chem., 366(6-7), pp.769-779.

13. Dubey, R. S. and Upadhyay, S. N. (2001) Biosens. Bioelectron., 16(9-12), pp.995 1000. DOI: $10.1016 /$ S0956-5663(01)00203-2

14. Degrassi, G.; Aguilar, C.; Bosco, M.; 
Zahariev, S., et al. (2002)Curr. Microbiol, 45, pp.250-254.

DOI: $10.1007 / \mathrm{s} 00284-002-3704-y$

15. Hansen, L. H. and Srrensen, S. J. (2001) Microb. Ecol., 42, pp.483-494. DOI: $10.1007 / \mathrm{s} 00248-001-0025-9$

16. Mitchel 1, R. J. and gU, m. b. (2003) Appl. Microbiol. Biotechnol.,Online First,

17. Kasemo, B. (2002) Surf. Sci., 500(1-3), pp.656-677.

DOI: 10.1016/S0039-6028(01)01809-X

18. Hutvagner, G. and Zamore, P. D. (2002) Curr. Opin. Genet. Dev.,12, pp.225-232. DOI: $10.1016 / \mathrm{S} 0959-437 \mathrm{X}(02) 00290-3$

19. Tomita, N.; Azuma, H.; Kaneda, Y.; Ogihara, T., et al. (2003)Curr. Drug Targets, 4, pp.339-346.

DOI: $10.2174 / 1389450033491055$

20. Tomita, N.; Ogihara, T. and Morishita, R. (2003) Curr. DrugTargets, 4, pp.603-608. DOI: $10.2174 / 1389450033490803$

21. Mountain, A. (2000) Trends Biotechnol., 18, pp.119-127

DOI: 10.1016/S0167-7799(99)01416-X

22. T. Kubik, K. Bogunia-Kubik and $M$. Sugisaka, Nanotechnology on Duty in Medical Applications, Current Pharmaceutical Biotechnology, 2005, 6,1733 DOI: $10.2174 / 1389201053167248$

23. Knight, C. G. (1981) Liposomes from physical structure totherapeutic applications, Elsevier, Amsterdam

24. Fattal, E.; Rojas, J.; Youssef, M.; Couvreur, P., et al. (1991)Antimicrob. Agents Chemother., 35, pp.770-772 DOI: 10.1128/AAC.35.4.770

25. Fattal, E.; Rojas, J.; Youssef, M.; Couvreur, P., et al. (1991)Antimicrob. Agents Chemother., 35, pp.770-772. DOI: 10.1128/AAC.35.4.770

26. Barratt, G.; Courraze, G.; Couvreur, P.; Dubernet, C., et al. (2002)in Polymeric biomaterials, (Dumitriu, S., Ed). Dekker, New York,pp.753-782.

27. Langer, R. (2000) Acc. Chem. Res., 33, pp.94-101. DOI: $10.1021 / \operatorname{ar} 9800993$

28. Barratt, G. (2003) Cell. Mol. Life Sci., 60, pp.21-37. DOI: $10.1007 / \mathrm{s} 000180300002$

29. Whelan, J. (2001) Drug Discov. Today, 6(23),

pp.1183-1184.

DOI: $10.1016 / \mathrm{S} 1359-6446(01) 02055-4$

30. Aboubakar, M.; Couvreur, P.; PintoAlphandary, H.; Gouritin, B.,et al. (2000) Drug Dev. Res., 49, pp.109-117. DOI: $\quad 10.1002 /($ SICI)10982299(200002)49:2<109::AID-

DDR4>3.0.CO;2-\#

31. Damage, C.; Vonderscher, J.; Marbach, P. and Pinget, M. (1997)Pharm. Res., 18, pp.949-954.

32. Fernandez-Urrusuno, R.; Calvo, P.; Remunan-Lopez, C.; Vila-Jato,J. L., et al. (1999) Pharm. Res., 16, pp.1576-1581. DOI: $10.1023 / \mathrm{A}: 1018908705446$

33. Guteress, S. S.; Fessi, H.; Barratt, G.; Puisieux, F., et al. (1995)Pharm. Res., 12, pp.1545-1547.

DOI: 10.1023/A:1016208125979

34. Guteress, S. S.; Fessi, H.; Barratt, G.; Puisieux, F., et al. (2000) J.Biomater. Sci. Polymer, 11, pp.1347-1355.

35. Gref, R.; Domb, A.; Quellec, P.; Blunk, T., et al. (1995) Adv. DrugDeliv. Rev., 16, pp.215233.

DOI: $10.1016 / 0169-409 X(95) 00026-4$

36. Bazile, D.; Prud'Homme, C.; Bassoulet, M.T.; Marland, M., et al.(1995) J. Pharm., 84, pp.493-498

37. Brigger, I.; Chaminade, P.; Marsaud, V.; Appel, M., et al. (2001)Int. J. Pharm., 214, pp.37-42.

DOI: $10.1016 / \mathrm{S} 0378-5173(00) 00628-1$

38. Avgoustakis, K.; Beletsi, A.; Panagi, Z.; Klepetsanis, P., et al.(2002) J. Controled Release, 79, pp.123-135. DOI: $10.1016 / \mathrm{S} 0168-3659(01) 00530-2$

39. Mosqueira, V. C. F.; Legrand, P.; Gulik, A.; Bourdon, O., et al.(2001) Biomaterials, 22, pp.2967-2979.

DOI: $10.1016 / \mathrm{S} 0142-9612(01) 00043-6$ 
40. Bourdon, O.; Mosqueira, V.; Legrand, P. and Blais, J. (2000) J.Photochem. Photobiol. B, 55, pp.164-171. DOI: $10.1016 / \mathrm{S} 1011-1344(00) 00043-9$

41. Jaulin, N.; Appel, M.; Passirani, C.; Barratt, G., et al. (2000) J.Drug Target, 8, pp.165172. DOI: $10.3109 / 10611860008996862$

42. West, J. L. and Halas, N. J. (2000) Curr. Opin. Biotechnol., 11,pp.215-217 DOI: $10.1016 / \mathrm{S} 0958-1669(00) 00082-3$

43. Lambert, G.; Fattal, E. and Couvreur, P. (2001) Adv. Drug Deliv.Rev., 47, pp.99-112. DOI: $10.1016 / \mathrm{S} 0169-409 \mathrm{X}(00) 00116-2$

44. Cunningham, C. C.; Holmlund, J. T.; Geary, R. S.; Kwoh, T. J., etal. (2001) Cancer, 92, pp.1265-1271. DOI: 10.1002/10970142(20010901)92:5<1265::AID-

CNCR1447>3.0.CO;2-5

45. Rudin, C. M.; Holmlund, J.; Fleming, G. F.; Mani, S., et al. (2001)Clin. Cancer Res., 7, pp.1214-1220.

46. Morris, M. J.; Tong, W. P.; Cordon_Cardo, C.; Drobnjak, M., et al.(2002) Clin. Cancer Res., 8, pp.679-683.

47. Mani, S.; Rudin, C. M.; Kunkel, K.; Holmlund, J. T., et al. (2002)Clin. Cancer Res., 8, pp.1042-1048.

48. Waters, J. S.; Webb, A.; Cunningham, D.; Clarke, P. A., et al.(2000) J. Clin. Oncol., 18, pp.1812-1823.

49. Gewirtz, A. M. (1999) Oncogene, 18(19), pp.3056-3062. DOI: 10.1038/sj.onc. 1202785

50. Marcucci, G.; Byrd, J. C.; Dai, G.; Klisovic, M. I., et al. (2003)Blood, 101, pp.425-432. DOI: 10.1182/blood-2002-06-1899

51. Luger, S. M.; O_Brien, S. G.; Ratajczak, J.; Ratajczak, M. Z., et al.(2002) Blood, 99, pp.1150-1158.

DOI: 10.1182/blood.V99.4.1150

52. Loke, S. L.; Stein, C. A.; Zang, X. H.; Mori, K., et al. (1989) Proc.Natl. Acad. Sci. USA, 86 ,

DOI: $10.1073 /$ pnas.86.10.3474

53.Yakubov, L. A.; Deeva, E. A.; Zarytova, V. F.; Ivanova, E. M., etal. (1989) Proc. Natl.
Acad. Sci. USA, 86, pp.6454-6458. DOI: $10.1073 /$ pnas.86.17.6454

54. Lambert, G.; Fattal, E. and Couvreur, P. (2001) Adv. Drug Deliv.Rev., 47, pp.99-112. DOI: $10.1016 / \mathrm{S} 0169-409 \mathrm{X}(00) 00116-2$

55. Lambert, G.; Bertrand, J. R.; Fattal, E.; Subra, F., et al. (2000)Biochem. Biophys. Res. Commun., 91, pp.118-126.

56. Hohjoh, H. (2002) FEBS Lett., 521(1-3), pp.195-199.

DOI: $10.1016 / \mathrm{S} 0014-5793(02) 02860-0$

57. Hutvagner, G. and Zamore, P. D. (2002) Curr. Opin. Genet. Dev.,12, pp.225-232. DOI: $10.1016 / \mathrm{S} 0959-437 \mathrm{X}(02) 00290-3$

58. Tomita, N.; Azuma, H.; Kaneda, Y.; Ogihara, T., et al. (2003)Curr. Drug Targets, 4, pp.339-346.

DOI: $10.2174 / 1389450033491055$

59. Tomita, N.; Ogihara, T. and Morishita, R. (2003) Curr. DrugTargets, 4, pp.603-608. DOI: $10.2174 / 1389450033490803$

60. Mountain, A. (2000) Trends Biotechnol., 18, pp.119-127.

DOI: $10.1016 / \mathrm{S} 0167-7799(99) 01416-X$

61. Maksymowych, W. P.; Blackburn, W. D.; Tami, J. A. and Shanahan, W. R. (2002) J. Rheumatol., 29, pp.447-453.

62. Muul, L. M.; Tuschong, L. M.; Soenen, S. L.; Jagadeesh, G. J., etal. (2003) Blood, 101, pp.2563-2569.

DOI: 10.1182/blood-2002-09-2800

63. Kay, M. A.; Manno, C. S.; Ragni, M. V.; Larson, P. J., et al. (2000) Nat. Genet., 3, pp.257-261. DOI: 10.1038/73464

64. Manno, C. S.; Chew, A. J.; Hutchison, S.; Larson, P. J., et al.(2003) Blood, 101, pp.2963-2972.

DOI: 10.1182/blood-2002-10-3296

65. Roth, D. A.; Tawa, N. E.; O'Brien, J. M.; Treco, D. A., et al. (2001)N. Engl. J. Med., 344(23), pp.1735-1742. DOI: 10.1056/NEJM200106073442301

66. Davis, S. S. (1997) Trends Biotechnol., 15, pp.217-224.

DOI: $10.1016 / \mathrm{S} 0167-7799(97) 01036-6$ 
67. Ulmer, J. B.; Sadoff, J. C. and Liu, M. A. (1996) Curr. Opin.Immunol., 8, pp.531-536. DOI: $10.1016 / \mathrm{S} 0952-7915(96) 80042-2$

68. Dubensky, T. W.; Liu, M. A. and Ulmer, J. B. (2000) Mol. Med., 6,pp.723-732

69. Cui, Z. and Mumper, R. J. (2001) J. Controled Release, 75, pp.409-419. DOI: $10.1016 / \mathrm{S} 0168-3659(01) 00407-2$

70. Shi, Z.; Curiel, D. T. and Tang, D. C. (1999) Vaccine, 17(17),pp.2136-2141. DOI: $10.1016 / \mathrm{S} 0264-410 \mathrm{X}(98) 00488-5$

71. Cui, Z. and Mumper, R. J. (2001) J. Controled Release, 75, pp.409-419. DOI: $10.1016 / \mathrm{S} 0168-3659(01) 00407-2$

72. Shi, Z.; Curiel, D. T. and Tang, D. C. (1999) Vaccine, 17(17),pp.2136-2141. DOI: $10.1016 / \mathrm{S} 0264-410 \mathrm{X}(98) 00488-5$

73. Saxl, O., pp.82-85.

74. Saxl, O. (2003) Pharm. J., 271, p.362

75. Orive, G.; Hernandez, R. M.; Gascon, A. R.; Calafiore, R., et al.(2003) Nat. Med., 9, pp.104-107. DOI: 10.1038/nm0103-104

76. Chang, T. M. (2003) Artif. Cells Blood Substit. Immobil.Biotechnol., 31, pp.151161. DOI: $10.1081 / \mathrm{BIO}-120020173$

77. Pohorille, A. and Deamer, D. (2002) Trends Biotechnol., 20,pp.123-128. DOI: $10.1016 / \mathrm{S} 0167-7799(02) 01909-1$

78. Chang, T. M. S. (1999) Trends Biotechnol., 17 , pp.61-67. DOI: $10.1016 / \mathrm{S} 0167-7799(98) 01242-6$

79. Chang, T. M.; Powanda, D. and Yu, W. P. (2003) Artif. Cells,Blood Subtit. and Immobil. Biotech., 31, pp.231-247. DOI: $10.1081 / \mathrm{BIO}-120023155$

80. Chang, T. M. (2003) J. Intern. Med., 253, pp.527-535. Freitas, R. A. (1996) Nanotechnol. Mag., 2, pp.8-13.

82. Freitas, R. A. (1998) Artif. Cells, Blood Subtit. and Immobil.Biotech., 26, pp.411430.

83. Drexler, K. E. (1981) Proc. Natl. Acad. Sci.
USA, 78, pp.5275-5278.

DOI: $10.1073 /$ pnas.78.9.5275

84. Drexler, K. E. (1986) Engines of Creation: The Coming Era ofNanotechnology, Anchor Press / Doubleday, New York.

85. Drexler, K. E. (1992) Nanosystems: Molecular Machinery,Manufacturing, and Computation, John Wiley \& Sons, New York.

86. Merkle, R. C. (1996) in Advances in AntiAging Medicine, (Klatz, R. M., Ed). Liebert Press, pp.277-286.

87. Taton, T. A. (2001) Nature, 412(6846), pp.491-492 DOI: $10.1038 / 35087687$

88. Freitas, R. A. (2002) Stud. Health. Technol. Inform., 80, pp.45-59.

89. Freitas, R. A. (1996) Nanotechnol. Mag., 2, pp.8-13.

90.Freitas, R. A. (1998) Artif. Cells, Blood Subtit. and Immobil.Biotech., 26, pp.411430.

91. Fahy, G. M. (1993) Clin. Chem., 39, pp.2011-2016.

92. Fahy, G. M. (1993) in 2020 Visions: Health Care Information Standards and Technologies, (Bezold, C.; Halperin, J. A. and Eng,J. L., Eds). U.S. Pharmacopeial Convention, Rockville MD,pp.152-159.

93.Triggle, D. J. (1999) Ann. Pharmacother., 33, pp.241-246. DOI: 10.1345/aph.18337

94. Freitas, R. A. (1996) Analog, 116, pp.57-73.

95.Lampton, C. (1995) Genet. Eng. News, 4, p. 23

96. PEIXE, T., SOUZA NASCIMENTO, E. , SCHOFIELD, K. , ARCURI, A. and BULCÃO, R. (2015) Nanotoxicology and Exposure in the Occupational Setting. Occupational Diseases and Environmental Medicine, 3, 35-48. DOI: 10.4236/odem.2015.33005 